\title{
DÜĞÜMLER ARASINDA DİREKT GİDİŞE MÜSAADE EDEN KAPASİTE KISITLI, ÇOK ATAMALI ANA DAĞITIM ÜSSÜ YER SEÇİM PROBLEMİ
}

\author{
Sinan AYGÜN ${ }^{1}$, Erkan KÖSE ${ }^{2}$, Hakan Soner APLAK ${ }^{3}$ \\ ${ }^{1}$ Genel Kurmay Başkanlığı, 06400 Çankaya, Ankara \\ ${ }^{2}$ Kara Harp Okulu, Savunma Bilimleri Enstitüsü, 06400 Çankaya, Ankara \\ ${ }^{3}$ Kara Harp Okulu, Endüstri ve Sistem Mühendisliği Bölümü, 06400 Çankaya, Ankara \\ sinanaygun2005@yahoo.com.tr, erkankose93@gmail.com, haplak@kho.edu.tr
}

(Geliş/Received: 25.01.2015; Kabul/Accepted: 11.09.2015)

ÖZET

Ana dağıtım üsleri (ADÜ) çoktan-çoğa dağıtım sistemlerinde toplama, sınıflandırma ve aktarma noktası olarak hizmet veren özel tesislerdir. ADÜ yer seçim problemlerinde, kaynak-varış noktaları arasındaki akışlar doğrudan birbirleri arasında değil, ölçek ekonomisinden faydalanmak amacıyla ana dağıtım üsleri aracılığıyla gerçekleştirilir. Bu sayede daha az bağlantı hattı ve daha düşük maliyetlerle daha fazla noktaya bağlantı sağlanmış olur. Bu çalışmada, bir kamu kurumuna yönelik gerçek bir ana dağıtım üssü yer seçim problemi ele alınmıştır. Kurumun talepleri ve problemin gereksinimlerinden yola çıkılarak, literatürde yer alan kapasite kısıtlı ve çok atamalı yapıya sahip ADÜ yer seçim problemlerine yeni boyut kazandırılmıştır. Literatürde yer alan çalışmalardan farklı olarak, ADÜ olarak seçilmeyen kaynak-varış çiftleri arasındaki akışlarda ADÜ kullanma zorunluluğu gevşetilmiş ve ADÜ olarak seçilen düğümlerin kapasitelerinin hem ADÜ, hem de ADÜ olarak seçilmeyen dügü̈mlerden gelen akışlardan etkilenmesi sağlanmıştır.

Anahtar Sözcükler: Tesis yeri seçimi, ana dağıtım üssü yer seçimi, matematiksel modelleme

\section{CAPACITATED MULTIPLE ALLOCATION HUB LOCATION PROBLEM WHICH ALLOWS DIRECT FLOW BETWEEN NODES}

\begin{abstract}
Hubs are special facilities that serve as switching, transshipment and sorting points in many-to-many distribution systems. In hub location problems, transfers between origin-destination points do not take place directly between each other, but by means of hubs for the purpose of taking advantages of economies of scale. Thus, it becomes possible to provide connections to more points with less lines and costs. In this study, a real hub location problem is studied for a public institution. On the basis of the institutions' demands and the problems' requirements, a new dimension has been provided to the capacitated multiple allocation hub location problems which have significance in the literature. Unlike the studies conducted in the literature, obligation to use hubs among the origin-destination pairs that are unselected hub is relaxed and the capacities of nodes that are selected as hubs are provided to be affected by the flows both from the hubs and the spokes.
\end{abstract}

Keywords: Facility location, hub location, mathematical modeling

\section{GÍRISŞ (INTRODUCTION)}

Ana Dağıtım Üssü (ADÜ) yer seçim problemleri, son 25 yıldır yerleşim teorisinin önemli bir araştırma alanı haline gelmiştir. Bunda modern taşımacılık ve telekomünikasyon sistemlerinde topla-dağıt ăg yapılarının kullanımının büyük rolü vardır. Topla- dağıt ağ yapısında, merkezi konumda olan bir tesis, toplama ve dağıtma noktası olarak hizmet verir. Toplama ve dağıtma noktası olarak kullanılan bu merkez "ana dağıtım üssü" olarak isimlendirilir. Ana dağıtım üsleri, çoktan-çoğa dağıtım sistemlerinde toplama, sınıflandırma ve aktarma noktası olarak hizmet veren özel tesislerdir. Tüm kaynak-varış 
noktası arasındaki akışlar doğrudan birbirleri arasında değil, bunun yerine, ölçek ekonomisinden faydalanmak amacıyla ana dağıtım üslerinde toplanır ve yine ana dağıtım üsleri üzerinden varış noktalarına gönderilir. Bu sayede daha az bağlantı hattı ve daha düşük maliyetlerle daha çok noktaya erişim sağlanmış olur. Bu çalışmada, dönemsel olarak çalışanlarının bir kısmını Erzincan-Elazığ-Diyarbakır-Mardin hattının batısındaki illerden hattın doğusundaki illere, hattın doğusundaki illerden hattın batısındaki illere ve hattın doğusundaki iller arasında taşınması gereken bir kamu kurumuna yönelik gerçek bir ana dağıtım üssü yer seçim problemi ele alınmıştır. Problemde, çalışanlar, hem kara hem de havayolu ile taşınabilmektedir. Güvenlik nedeni ile bazı yollar arasında kara yolu taşımacılığının maliyeti çok yüksektir. Literatürde yer alan çalışmalar incelendiğinde ADÜ yer seçim problemlerinin çözümü için geliştirilen matematiksel modellerin ele alınan problemin temel karakteristiklerini karşılamada yetersiz kaldığı görülmüştür. Kurumun talepleri ve problemin gereksinimlerinden yola çıkılarak, Marin [1] tarafından önerilen, kapasite kısıtlı ve çok atamalı yapıya sahip ADÜ yer seçim problemlerine yeni boyut kazandırılmıştır. Geliştirilen modelde Marin'in çalışmasından farklı olarak;

- ADÜ olarak seçilmeyen kaynak-varış çiftleri arasındaki akışlarda ADÜ kullanmadan direkt gidişe izin verilmiş,

- ADÜ olarak seçilen düğümlerin kapasitelerinin, hem ADÜ, hem de ADÜ olarak seçilmeyen dügümlerden gelen akışlardan etkilenmesi sağlanmıştır.

Çalışmanın bundan sonraki bölümünde ADÜ yer seçim problemleri ile ilgili literatür araştırması yer almaktadır. Üçüncü bölümde ADÜ yer seçim problemleri hakkında temel bilgilere yer verilmiştir. Dördüncü bölümde, çalışmaya konu olan problem detaylı olarak açıklanmış ve problemin çözümü için geliştirilen matematiksel model sunulmuştur. Çalışmanın son bölümünde ise elde edilen sonuçlar değerlendirilmiş ve ileride yapılacak çalışmalar için öneriler sunulmuştur.

\section{LITERATÜR ARAŞTIRMASI (LITERATURE REVIEW)}

ADÜ yer seçim problemi ilk olarak O'kelly [2] tarafindan ortaya konulmuştur. O'kelly bu çalışmada, bir ve iki ADÜ bulunan temel modelleri geliştirmiş ve her başlangıç-varış çifti için doğrudan atamalarla oluşacak bağlantı sayısının, akışların ADÜ'ler üzerinden gönderilmesi durumunda azalacağına dikkat çekmiştir. ADÜ yer seçim problemi ile ilgili ilk matematiksel model, hava yolu taşımacılığı ağıyla ilgili çalışmasıyla yine O'kelly [3] tarafindan geliştirilmiştir. O'kelly bu problemi, minimum toplam problemi olarak isimlendirmiştir. O'kelly, Sivil
Havacılık Kurulu (Civil Aeronautics Board (CAB)) tarafindan 1970 yılına ait tutulan 25 ABD şehri arasındaki havayolu yolcu taşımacılığı ile ilgili bir veri seti oluşturmuştur. Daha sonra bu veri seti hemen hemen her ADÜ yer seçim problemi çalışan araştırmacı tarafından kullanılmış ve CAB veri seti olarak referans gösterilmiştir. Bir başka çok kullanılan veri seti ise Avustralya posta servisi veri setidir (AP) ve ilk olarak Ernst ve Krishnamoorthy [4] tarafindan kullanılmıştır. AP veri seti Avustralya/Sidney'e ait posta bölgelerini tanımlayan ve 200 düğümden oluşan bir veri setidir. $\mathrm{AP}$ veri setinin, $\mathrm{CAB}$ veri setinden düğüm sayısının fazla olması dışındaki en önemli farkı, AP veri setinde düğümler arasındaki akışların simetrik olmamasıdır [5]. ADÜ yer seçim problemleriyle ilgili ilk çalışmalar düşünüldüğünde, O’kelly'nin geliştirdiği karesel amaç fonksiyonuna sahip matematiksel model kritik bir role sahiptir [3, 6]. Daha sonra Campbell [7, 8] ADÜ yer seçim problemleriyle ilgili benzer amaç fonksiyonlarına sahip birçok matematiksel model önermiştir. Ayrıca, Aykin [9-12] akışa dayalı atama yaklaşımı ile ve Klincewicz [13, 14] hem akışa hem mesafeye bağlı atama prosedürü ile alanın genişlemesinde kritik rol oynamışlardır.

$\mathrm{Bu}$ çalışmaya konu teşkil eden kapasite kısıtlı, çok atamalı ADÜ yer seçim problemleri ile ilgili ilk matematiksel model Campbell [7] tarafindan geliştirilmiştir. Daha sonra Ebery ve ark. [15] kapasite kısıtlı çok atamalı ADÜ yer seçim problemini posta dağıtım ağı için düşünmüşler, seçilecek olan ADÜ'lerin kapasitesini, yalnızca postaları toplama aşamasının etkileyeceğini söyleyerek iki farklı model sunmuşlardır. Sasaki ve Fukushima [16], kapasite sınırlaması olan çok atamalı ADÜ yer seçim problemine yönelik bir model sunmuştur. Bu modelde hem ADÜ'ler, hem de ayrıtlar için kapasite sınırı uygulanmıştır. Boland ve ark. [17], kapasite kısıtlı ve kapasite kısıtsız çok atamalı ADÜ yer seçim problemlerinin optimal çözümlerinin bazı özelliklerini özetlemişlerdir. Yazarlar, hali hazırdaki karışık tamsayılı doğrusal programlama modellerine doğrusal programlama gevşetmesi geliştirebilmek için, optimal çözümlerin incelenmesi neticesinde buldukları sonuçlara dayanarak, önişlem prosedürleri ve sıkılaştırma kısıtları geliştirmişlerdir.

Marin [1], çok atamalı, kapasite kısıtlı ADÜ yer seçim problemleri için, Ebery ve ark. [15] tarafindan geliştirilen model ile aynı fikre dayanarak, ADÜ olmayan iki düğüm arasında direkt akışa izin vermeyen yeni bir model önermiştir. Rodriguez ve ark. [18], yeni bir model önermişlerdir. Bu modelde, her bir ADÜ kapasite kısıtlı olarak düşünülmüş ve $M / M / 1$ kuyruk sistemi ile modellenmiştir. Geliştirilen model, yazarlar tarafindan tavlama benzetimi algoritması ile çözülmüştür. Rodriguez ve Salazar [19], düğümler arasındaki bağlantıları ve ADÜ'leri kapasite kısıtlı olarak düşünmüşler ve tam bağlı 
olmayan bir şebeke için yeni bir karışık tamsayılı model önermişlerdir. Önerilen model iki ayrı dal sınır tabanlı ayrıştırma tekniğiyle çözülmüştür. Gelareh ve Pisinger [20], derin deniz servis sağlayıcısı dağıtımı için yeni bir karışık tamsayılı model önermişlerdir. Sender ve Clausen [21], çok atamalı, kapasite kısıtlı Alman yük taşıma problemi için yeni bir matematiksel önermişlerdir. Araştırmacılar problemi özel bir veri seti kullanarak CPLEX çözücüsü ve geliştirdikleri yerel iyileştirme tabanlı sezgisel ile çözmüşlerdir. Shahabi ve Unnikrishnan [22], talep ve dağıtımların tam belli olmadığı tek ve çok atamalı ADÜ yer seçim problemi için karışık tamsayılı doğrusal olmayan bir matematiksel model önermişlerdir. Karimi ve Setak [23], şebekedeki düğümlerin tam bağlı olmadığı çok atamalı ADÜ yer seçim problemi için matematiksel model önermiş ve çalışmalarında, geliştirdikleri modelin ilave edilecek birkaç kısıt ile diğer ADÜ yer seçim problemlerinde de kullanılabileceğini belirterek en iyi çözümlere ulaşmışlardır. Yukarıda yer alan çalışmalar incelendiğinde, şimdiye kadar yapılmış olan çalışmaların bu çalışmada ele alınan problemin temel karakteristiklerini karşılamada yetersiz kaldığ görülmüştür. $\mathrm{Bu}$ çalışmada literatürde yer alan çalışmalardan farklı olarak, ADÜ olarak seçilmeyen kaynak-varış çiftleri arasındaki akışlarda ADÜ kullanma zorunluluğu gevşetilmiş ve ADÜ olarak seçilen düğümlerin kapasitelerinin hem ADÜ, hem de ADÜ olarak seçilmeyen düğümlerden gelen akışlardan etkilenmesi sağlanmıştır.

\section{ADÜ YER SEÇIM PROBLEMLERİ (HUB LOCATION PROBLEMS)}

Ana dağıtım üssü yerleşim problemleri genel anlamıyla ana dağıtım üslerinin seçilmesi ve ana dağıtım üssü olmayan noktaların ana dağıtım üslerine atanmasını içeren yerleştirme atama problemidir [5]. ADÜ yer seçim probleminin özünde kaynak, varış ve potansiyel ADÜ noktalarının tanımlandığı $n$ adet düğüm noktasından oluşan bir ağ yapısı söz konusudur. ADÜ'ler kaynak-varış çiftleri arasındaki akışlar için aktarma ve birleştirme noktaları olarak hizmet verirler. Bir ADÜ, birçok ayrı küçük akışı daha büyük akışlara yönlendirir veya birleştirir. Problemin temel parametreleri; her kaynak-varış çifti arasındaki akış, birim taşıma maliyeti (maliyet, zaman, mesafe vb.) ve ADÜ'ler arasindaki taşımalarda ölçek ekonomisinden faydalanmak amacıyla kullanılan maliyet azaltma faktörü $(\alpha)$ 'dür [24]. ADÜ yer seçim problemi konusunda yapılan çalışmalar genellikle şu üç kabul üzerine inşa edilmiştir [25]:

- ADÜ ağ yapısı, her ADÜ çifti arasında bağlantı olacak şekilde tam serimlidir,

- ADÜ’ler arası bağlantıda maliyet azaltma faktörü $(\alpha)$ kullanılarak ölçek ekonomisinden faydalanılır,

- ADÜ olmayan dügüüler arasında direkt bağlantıya izin verilmez.
Ana dağıtım üssü yerleşim problemleri ADÜ yer seçimi ve düğüm noktalarının belirlenen ADÜ'lere atanması olmak üzere iki alt problemi kapsar [26]. Genel bir ADÜ yer seçim problemi, birbirleri arasındaki akışların değiştiği $n$ adet düğümü içerir. Birinci adımda $n$ düğümden $p$ tanesi ADÜ olarak seçilir. ADÜ olarak seçilen düğümler kabul, elleçleme, yeniden dağıtım için birleştirme ve dağıtım merkezi olarak kullanılırlar. İkinci adımda düğümler problemin yapısına uygun olarak bir (tek atamalı) veya birden fazla (çok atamalı) ADÜ’ye atanır [27].

Şekil 1'de genel bir ADÜ yer seçim problemi için toplama-dağıtım süreci gösterilmiştir [28]. Şekilde, $i$ düğümünden $j$ düğümüne gidecek akışların ölçek ekonomisinden faydalanmak maksadiyla öncelikle $k$ ADÜ'sünde toplanması, (diğer düğümlerden $j$ düğümüne gidecek olan akışlar ile birlikte) daha sonra $l$ ADÜ'süne transfer edilmesi ve son olarak $l$ ADÜ'sünden $j$ düğümüne dağıtımı gösterilmektedir.

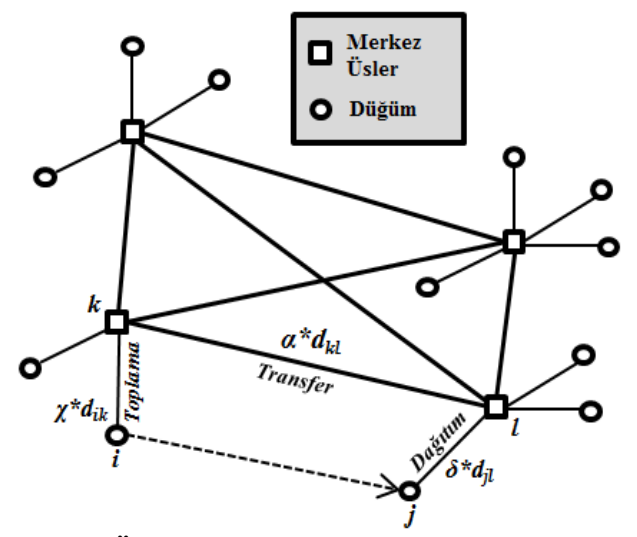

Şekil 1. ADÜ yer seçim probleminde toplama-dağıtım süreci (Hub location problem collection-distribution process)

$\chi \quad: i$ düğümünden $k$ ADÜ'süne gidişte maliyet azaltma katsayısını,

$\mathrm{d}_{\mathrm{ik}}: i$ düğümü ile $k$ düğümü arasındaki mesafeyi,

$\alpha$ : ADÜ'ler arasındaki transferde kullanılan maliyet azaltma katsayısını,

$\delta: l$ ADÜ'sünden $j$ düğümüne gidişte maliyet azaltma katsayısını ifade etmektedir.

ADÜ yer seçim problemleri ile ilgili en temel sınıflandırma Campbell [7] tarafindan yapılmıştır. Bu sinıflandırmaya göre ADÜ yer seçim problemleri şu dört başlık altında toplanmıştır;

- P-ADÜ Medyan Problemi,

- P-ADÜ Merkez Problemi,

- ADÜ Küme Kapsama Problemi,

- Sabit Maliyetli ADÜ Yer Seçim Problemidir.

P-ADÜ medyan probleminde ADÜ sayısı $p$ ile ifade edilen ve modeli geliştiren tarafindan belirlenen bir parametredir. P-ADÜ merkez problemi, p-merkez problemine benzer ve min-max tipinde bir problem çeşididir. Problemin ilk matematiksel modeli 
Campbell [7] tarafindan sunulmuştur. ADÜ küme kapsama problemi, ADÜ açma maliyetini minimize etmek maksadiyla, ADÜ’leri tüm düğümleri kapsayacak şekilde yerleştirme problemidir. Sabit maliyetli ADÜ yer seçim problemlerinde seçilecek ADÜ sayısı da bir karar değişkenidir ve problemin çözümü sonucunda belirlenir. Sabit maliyetli ADÜ yer seçim problemlerinde atamalar tek ve çok atamalı olmak üzere iki farklı şekilde yapılır. Tek atamalı yapıda her düğüm tek bir ADÜ'ye atanırken çok atamalı yapıda bir düğüm birden fazla ADÜ'ye atanabilmektedir. Şekil 2'de tek ve çok atamalar için örnek bir ADÜ yer seçim problemi gösterilmiştir [29].

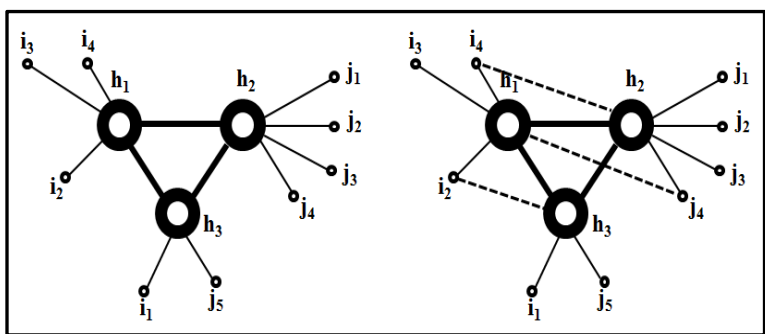

Şekil 2. Tek (a) ve çok (b) atamalı adü yer seçim problemi örnek ağ yapıları (Examples of single and multiple allocation hub location problem network structures)

\section{UYGULAMA (APPLICATION)}

Bu çalışmada, bir kamu kurumuna ait gerçek bir ana dağıtım üssü yer seçim problemi ele alınmıştır. Kamu kurumu, dönemsel olarak, çalışanlarının bir bölümünü Erzincan - Elazığ - Diyarbakır - Mardin hattının batısındaki illerden hattın doğusundaki illere, hattın doğusundaki illerden hattın batısındaki illere ve hattın doğusundaki iller arasında güvenli bir şekilde sevk etmesi gerekmektedir.

Problemde, çalışanlar, hem kara hem de hava yolu ile taşınabilmektedir. Güvenlik nedeni ile bazı yollar arasında kara yolu taşımacılığının maliyeti çok yüksektir. Belirlenen hattın batısındaki iller arası personel sevkiyatı çalışanların kendi imkânları ile gerçekleştirilmektedir ve bu çalışmada kapsam dişı bırakılmıştır. Hali hazırda işletilmekte olan sistemde, çalışanlar, gidecekleri noktalara kurumun belirlediği güzergâhlara göre, sadece kara yolunu ya da hava yolunu veya kara yolu ve hava yolunu birlikte kullanarak gidebilmektedir. Hava yolu taşımacılığ için belirlenen hattın batısında bulunan 12 ilin havaalanı ile doğusunda bulunan 9 ilin havaalanı kullanılmaktadır. Hava yolunu kullanacak personel nereye giderse gitsin 21 hava alanı içerisinden kendisine en yakın hava alanından başkasını kullanamamaktadır.

Hava yolu şirketleri ile toplu ulaşım için anlaşma yapılabileceği değerlendirilmektedir ancak mevcut durumda hava yolu sevkleri bireysel olarak yapılmaktadır. Mevcut sistemdeki personel sevkini bir örnekle açıklayacak olursak; Siirt'ten Tunceli'ye sevk edilen bir personel önce kendisine en yakın hava alanı olan Batman hava alanını kullanarak Ankara veya İstanbul'a oradan da Elazığ'a hava yolu ile sevk edilmekte, Elazığ'dan Tunceli'ye kara yolu ile gitmektedir. Hali hazırda hava yolu şirketleri ile herhangi bir anlaşma bulunmadığından hava yolu ulaşımı için tarifeli seferlere bağlı kalınmakta bu da gereksiz uçuş maliyetleri ve zaman kaybına yol açmaktadır.

Problemin tasarlanması aşamasında ilk olarak kurum yönetiminin istekleri tespit edilmiştir. $\mathrm{Bu}$ istekler şu şekilde sıralanmıştır:

- Çalışanların tamamının mümkün olduğunca hava yolu ile taşınması,

- Batıdaki illerden, Erzincan, Elazığg, Diyarbakır ve Mardin illerine kara yolu ile taşıma yapılabilmesi,

- Batıdaki illerden, Erzincan, Elazı̆̆g, Diyarbakır, Mardin illerinin doğusunda bulunup bu illere komşu olan ve kurumun müsaade ettiği illere kara yolu ile taşıma yapılabilmesi,

- Belirlenen hattın doğusunda sadece kurumun müsaade ettiği iller arasında kara yolu ile taşıma yapılabilmesi,

- Maliyet avantajı elde etmek için çalışanların gidecekleri noktalara bireysel olarak tarifeli uçaklarla gönderilmesi yerine belirlenen havaalanlarında toplanıp, uçak kiralama yöntemi ile toplu olarak taşınmaları istenmektedir.

Problemin çözümü için, kurum yönetiminin istekleri doğrultusunda geliştirilen matematiksel model yardımıyla aşağıdaki sorulara cevap aranmıştır:

- Bir sevk döneminde taşıtılması gereken personelin hangi vasıta ve hangi güzergâhı kullanarak sevk edileceği,

- Hangi havaalanlarının ADÜ olarak kullanılacağı ve hangi illerin bu ADÜ'lere atanacağı,

- Sistemin kaç adet ADÜ vasıtasıyla en ekonomik şekilde işletilebileceği,

- Hangi iller arasında ADÜ kullanmadan direkt gidişe müsaade edileceği.

Problem, şebekedeki düğümler arasındaki mesafelerde üçgensel eşitsizliğin sağlanamadığı, kesikli uzayda yer alan, kapasite kısıtlı, çok atamalı, eğer daha ekonomik ise ADÜ olarak seçilmeyen düğümler arasında direkt gidişe müsaade edildiği; ADÜ yer seçim problemi olarak tasarlanmıştır. Problemin yapısına uygun olarak bir matematiksel model geliştirmek için bu alandaki en önemli çalışmalardan birisi olan Marin [1] esas alınmış ve modele yeni boyutlar kazandırılmıştır.

Marin [1] bu çalışmasında, posta dağıtım ağı problemini düşünerek, şebekedeki düğümler arasındaki mesafelerde üçgensel eşitsizliğin sağlanamadığı, kapasite kısıtlı, çok atamalı ADÜ yer 
seçim problemleri için bir matematiksel model önermiştir. Çalışmada, düğümler arasındaki mesafelerde üçgensel eşitsizliğin sağlanamadığ durumda, şebekedeki akışların ikiden fazla ADÜ gezerek maliyetlerin yanlış hesaplanmasına sebep olacağını vurgulamış ve posta dağııı ağında, postaların ADÜ'lere ulaştığında tasnif edildiği ve bu postalara bir daha işlem yapılmadığ düşüncesinden hareketle, ADÜ'lerin kapasitelerini yalnızca ADÜ olmayan dügümlerden gelen akışların etkilediğini belirtmiştir.

$\mathrm{Bu}$ çalışmada, ele alınan problemin yapısı gereği Marin [1]'in geliştirdiği modeldeki kapasite kısıtından farklı olarak yeni bir kapasite kısıtı geliştirilmişstir. Problemde, ADÜ'lerin kapasiteleri sadece ADÜ olarak seçilmeyen düğümlerden gelen akışlardan değil, aynı zamanda ADÜ olarak seçilen düğümlerden gelen akışlardan da etkilenmektedir. Çalışmada aynı zamanda Marin [1]'in modelinden farklı olarak kaynak-varış çiftleri arasındaki akışlarda ADÜ kullanma zorunluluğu gevşetilmiş ve ADÜ olarak seçilmeyen düğümler arasındaki akışlarda ADÜ kullanmadan direkt gidişe müsaade eden yeni kısıtlar geliştirilmiştir. Geliştirilen yeni kısıtlar vasıtasıyla;

- Batıdan, belirlenen hattın üzerinde bulunan illere olan akışların,

- Batıdan, belirlenen hattın üzerinde bulunan illere komşu ve kurumun müsaade ettiği illere olan akışların,

- Belirlenen hattın doğusunda bulunan ve kurumun müsaade ettiği iller arasındaki akışların, ADÜ kullanmadan direkt olarak gerçekleşmesi sağlanmış, böylece akışların daha fazla yol kat ederek fazla maliyete sebep olması engellenmiştir.

Matematiksel model kurum tarafindan uygun görülen şu varsayımlara dayalı olarak tasarlanmıștır:

• Düğüm-ADÜ arasındaki taşıma, karayolu ile bireysel olarak yapilacaktır.

- ADÜ-ADÜ arasındaki taşıma, hava yolu ile toplu olarak yapılacaktır.

- ADÜ-düğüm arasındaki taşıma, kara yolu ile toplu olarak yapilacaktır.

- Düğüm-düğüm arası taşımaların tamamı kara yolu ile bireysel olarak yapılacaktır.

- Kurum, çalışanlarını, bir yıl içerisinde dört dönem halinde sevk etmektedir. Çalışmada bir sevk dönemi ele alınmıştır.

- Matematiksel modelde kullanılan akışlar deterministik olarak ele alınmış ve akışların tamamının aynı zaman diliminde gerçekleştiği kabul edilmiştir.

Kurumun istekleri doğrultusunda oluşturulan matematiksel model ve modelde yer alan değişken/parametre tanımlamaları takip eden bölümlerde sunulmuştur.

\subsection{Parametreler (Parameters)}

Problemde "81" adet ili kapsayan tek bir küme $(N)$ bulunmaktadır. Dolayısıyla bütün indisler aynı küme içerisinde yer almakta ve aynı küme içerisinden seçilmektedir. İller plaka kodları ile ifade edilmiştir. ADÜ yer seçim problemlerinde, tüm düğümler aynı zamanda aday ADÜ durumundadır. Bu çalışmada ise, "81" adet düğüm aday ADÜ konumunda değildir. Kurum, personelinin mümkün olduğunca hava yolu ile taşıtılmasını istediğinden, düğümler arasında yer alan ve anlaşma yapılan firmanın uçaklarının iniş ve kalkış yapabildiği " 42 " adet havaalanı aday ADÜ olarak belirlenmiştir. Matematiksel modelde yer alan parametrelere ilişkin açıklamalar aşağıda sunulmuştur.

$W_{i j}: i$ kaynak noktasından $j$ varış noktasına akış miktarı $(i=1, \ldots, 81 ; j=1, \ldots, 81)$

$r_{i j} \quad: i$ kaynak noktası ile $j$ varış noktası arasındaki kara yolu mesafesi $(i=1, \ldots, 81 ; j=1, \ldots, 81)$

$h_{i j}: i$ kaynak varış noktası ile $j$ varış noktası arasindaki hava yolu mesafesi $(i=1, \ldots, 81 ; j=1, \ldots, 81)$

$\Gamma_{k}: k$ düğ̈̈münün kapasitesi $(k=1, \ldots, 81)$

$\alpha$ : Transfer için maliyet azaltma faktörü (ana dağıtım üssünden ana dağıtım üssüne), ADÜ yer seçim problemlerinde, ADÜ'ler arasındaki akışlarda ölçek ekonomisinden faydalanmak maksadiyla $\alpha$ adında ve değeri $0-1$ arasında olan bir sabit kullanılmaktadır. $\mathrm{Bu}$ çalışmada $\alpha$, kurum yetkilileri ile yapılan görüşme neticesinde, anlaşma yapılan firmanın tarifeli uçak ücretleri ve uçak kiralama fiyatları arasındaki farklar düşünülerek $\alpha=0.60$ olarak belirlenmiştir.

$\delta$ : Dağıtım için maliyet azaltma katsayısı (ana dağıtım üssünden ana dağıtım üssü olmayan varış noktasına).

$\delta$ katsayısı kurumun ADÜ’lerden diğer düğümlere dağıtım işlemlerinde kendi araçlarını kullanabilmesinden kaynaklanan maliyet azaltma katsayısıdır ve kurum yetkilileri ile yapılan görüşmeler neticesinde $\delta=0,80$ olarak belirlenmiştir. $\mathrm{Bu}$ katsayı belirlenirken personeli ADÜ’lerden diğer düğümlere toplu olarak sevk edebilmenin sağladığı ölçek ekonomisi dikkate alınmıştır.

б : kara yolu ile taşıma için bir km'lik maliyet katsayısı $(0,09 \mathrm{TL} / \mathrm{KM})$,

$\phi$ : hava yolu ile taşıma için bir km'lik maliyet katsayısı $(0,13 \mathrm{TL})$,

Dügü̈mler (iller) arası mesafeler $\left(r_{i j}\right.$ ve $h_{i j}$ değerleri) Karayolları Genel Müdürlüğü internet sayfasından alınmıştır [30]. Uzaklıklar matrisi, kara yolu ve hava yolu taşımacılığı için iki farklı şekilde düzenlenmiştir. Kara yolu taşımacılığı için oluşturulan uzaklıklar matrisinde, kurum tarafindan direkt gidilmesine müsaade edilmeyen iller arasındaki mesafeler için, matrisin ilgili hücresine büyük ceza katsayıları 
girilmiş ve bu gidişler engellenmiştir. Hava yolu taşımacılığı için oluşturulan uzaklıklar matrisinde, havaalanı bulunmayan iller arasındaki mesafeler için, matrisin ilgili hücresine büyük ceza katsayıları girilmiş ve bu gidişler engellenmiştir. Kara yolu taşımacılığı maliyetleri $\left(R_{i j}\right)$ ve hava yolu taşımacılığı maliyetleri $\left(H_{i j}\right)$ sirasıyla, uzaklık matrislerinin ilgili elemanlarının $\left(r_{i j}\right.$ veya $\left.h_{i j}\right)$, kurum tarafindan belirlenen bir km'lik kara yolu taşıma maliyet katsayısı $(\delta)$ ve bir km'lik hava yolu taşıma maliyet katsayısı $(\phi)$ ile çarpılması sonucu elde edilmiştir. Uzaklık matrislerinin ilgili hücrelerine girilmiş olan ceza sayıları problemde mesafeler arasında yer alan üçgensel eşitsizliği bozmuştur. Üçgensel eşitsizliğin sağlanamadığı problemlerde maliyetlerin doğru hesaplaması ve ADÜ yer seçim problemlerinin temel varsayımlarından biri olan, akışların en fazla iki ADÜ gezmesini sağlayabilmek için modele ilave kısıtlar eklemek gerekmektedir. Bu çalışmada da kaynakvarış çiftleri arasındaki akışların en fazla iki ADÜ gezerek gideceği noktaya ulaşmasını sağlamak için, Marin [1] tarafından geliştirilen kısıtlar kullanılmıştır. Sabit maliyetli ADÜ yer seçim problemlerinde, ADÜ olarak seçilen düğümler sabit bir kuruluş maliyetine sahiptir. Bu çalışma, sabit maliyetli, kapasite kısıtlı ADÜ yer seçim problemi olarak tasarlanmıştır. Ancak, işletilmekte olan sistemde, kurumun havaalanı bulunan her ilde kurulmuş olan ve hâlihazırda işleyen tesisleri vardır. Dolayısıyla, herhangi bir ilde bulunan havaalanının ADÜ olarak seçilmesi durumunda, yeniden kuruluş maliyeti söz konusu değildir. Mevcut durumda kullanılan bir tesisin ADÜ olarak seçilmemesi durumunda ise, bu tesis kurum tarafindan başka bir maksatla kullanılmaya devam edeceği ve tesis kapatma maliyetinin oluşmayacağ değerlendirilmiştir. Bu nedenle sabit kuruluş maliyeti problemin dişında bırakılmıştır.

\subsection{Karar Değişkenleri (Decision Variables)}

$a_{m j}: \quad m$ düğümünün $\mathrm{ADÜ}, j$ düğümünün $\mathrm{ADÜ}$ olmadığı durumda, $m$ düğümünden $j$ düğümüne giden akış miktarı,

$b_{k m j}: \quad k$ ve $m$ dügüumlerinin $\mathrm{ADÜ,} j$ düğümünün ADÜ olmadığı durumda, $k$ ve $m$ ADÜ'lerini kullanıp $j$ düğümüne giden akış miktarı,

$c_{i k j}: k$ düğümünün $\mathrm{ADÜ}, i$ düğümünün $\mathrm{ADÜ}$ olmadığı durumda, $i$ düğümünden çıkıp $k$ ADÜ'sünü kullanarak $j$ düğümüne giden akış miktarı,

$Y_{k}: k$ düğümünün ADÜ olduğu durumda “1”, diğer durumlarda " 0 " değerini alan ikili değişken,

$e_{i j} \quad: i$ ve $j$ düğümlerinin ADÜ olmadığı durumda, $i$ düğümünden $j$ düğümüne ADÜ kullanmadan direkt giden akış miktarıdır.

Modelde beş tip karar değişkeni bulunmaktadır. Birinci tip karar değişkeni (a), başlangıç noktasının ADÜ, varış noktasının ADÜ olmayan düğüm olduğu durumdaki akış miktarını belirtmektedir. İkinci tip karar değişkeni (b), başlangıç noktasının ve ikinci düğümün ADÜ olduğu durumdaki akış miktarının belirtmektedir. Üçüncü tip karar değişkeni (c), başlangıç noktasının ADÜ olmayan düğüm, ikinci düğümün ADÜ olduğu durumdaki akış miktarını belirtmektedir. Dördüncü tip karar değişkeni (e), başlangıç ve varış noktasının ADÜ olmayan düğüm olduğu durumda, ADÜ kullanılmadan, kaynak noktasından varış noktasına direkt giden akışı belirtmektedir. Beşinci tip karar değişkeni (Y), bir düğüm ADÜ olarak seçildiğinde "1", seçilmediğinde " 0 " değerini alan ikili değişkendir. Problemde yer alması muhtemel tüm alternatif yollar ve karar değişkenlerinin hangi durumlarda değer aldıkları Şekil 3'te sunulmuştur.

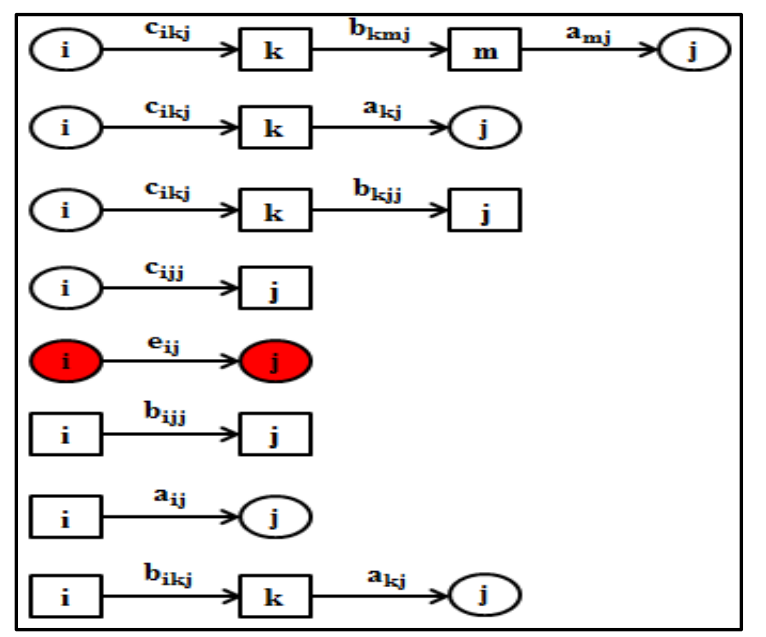

Şekil 3. Problemde yer alan muhtemel yollar ve karar değişkenlerinin görevleri (Possible routes and decision variables in the problem)

Şekil 3'te (1) numaralı alternatif yolda, başlangıç $i$ düğümü ADÜ olmayan nokta, $k$ ve $m$ düğümleri ADÜ, varış noktası olan $j$ düğümü ise ADÜ olmayan noktadır. $i$ ve $k$ düğümleri arasındaki akış $\mathrm{c}_{\mathrm{ikj}}$ karar değişkeni ile ifade edilmiştir. $c_{i k j}$ karar değişkeni başlangıç düğümünün ADÜ olmayan düğüm, ikinci düğümün ADÜ olduğu durumda değer alabilmektedir. Aynı akışın devamı olan $k$ ve $m$ düğümleri arasındaki akış $b_{k m j}$ karar değişkeni ile ifade edilmiştir. $b_{k m j}$ karar değişkenini birinci ve ikinci düğümün ADÜ olduğu durumda değer alabilmektedir. Aynı yolun sonundaki $m$ ve $j$ düğümleri arasındaki akış $a_{m j}$ karar değişkeni ile ifade edilmiştir. $a_{m j}$ karar değişkeni birinci düğümün ADÜ, ikinci düğümün ADÜ olmayan düğüm olduğu durumda değer alabilmektedir.

\subsection{Matematiksel Model (Mathematical Model)}

Matematiksel model; kapasite kısıtlı (ADÜ'lerin kapasitelerinin hem ADÜ, hem de ADÜ olarak seçilmeyen düğümlerden gelen akışlardan etkilendiği), çok atamalı, ADÜ olarak seçilmeyen düğümler arasında direkt gidişe müsaade eden, ADÜ yer seçim problemi olarak tasarlanmıştır. 


\section{Amaç Fonksiyonu}

$\operatorname{Min} \sum_{i} \sum_{k} \sum_{j} R_{i k} c_{i k j}+\sum_{k} \sum_{m} \sum_{j} \alpha H_{k m} b_{k m j}+$ $\sum_{m} \sum_{j} \delta R_{m j} a_{m j}+\sum_{i} \sum_{j} R_{i j} e_{i j}$

\section{Kisitlar}

$\sum_{m} a_{m j}+\sum_{m} b_{m j j}+\sum_{m} c_{m j j}+\sum_{m} e_{m j}=\sum_{i} W_{i j} \forall j$

$e_{i j}+a_{i j}+\sum_{k} b_{i k j}+\sum_{k} c_{i k j}=W_{i j}+\sum_{k} b_{k i j}+$

$\sum_{k} c_{k i j} \forall i, \forall j \neq i$,

$\sum_{k} b_{k m j}+\sum_{k} c_{k m j} \leq\left(\sum_{i} W_{i j}-W_{m j}\right) Y_{m} \quad \forall j, \forall m \neq j$

$\sum_{k} b_{k j j}+\sum_{k} c_{k j j}=\sum_{i} W_{i j} Y_{j} \quad \forall j$,

$c_{i k j} \leq W_{i j} Y_{k} \quad \forall i, j, k$,

$e_{i j}+\sum_{k} c_{i k j}=W_{i j}\left(1-Y_{i}\right) \quad \forall i, j$

$\sum_{m} b_{k m j} \leq W_{k j}+\sum_{i} c_{i k j} \quad \forall k, j$,

$\sum_{i} \sum_{j} c_{i k j}+\sum_{i} \sum_{j} b_{i k j} \leq \Gamma_{k} Y_{k} \quad \forall k$

$e_{i j} \leq W_{i j}\left(1-Y_{i}\right) \quad \forall i, j$

$e_{i j} \leq W_{i j}\left(1-Y_{j}\right) \quad \forall i, j$

$b_{j m j}=0 \quad \forall j, \forall m \neq j$,

$b_{k k j}=0 \quad \forall j, \forall k \neq j$,

$c_{k k j}=0 \quad \forall j, k$,

$a_{j j}=0 \quad \forall j$,

$Y_{k} \in\{0,1\} \quad \forall k$,

$b_{k m j}, c_{i k j}, a_{m j}, e_{i j} \geq 0 \quad \forall i, j, k, m$,

$i=1, \ldots 81 ; j=1, \ldots 81 ; k=1, \ldots 81 ; m=1, \ldots 81$

Modelin amaç fonksiyonu (1), toplam taşıma maliyetini minimize etmeyi hedeflemektedir. Amaç fonksiyonunun; birinci parçası, toplama (ADÜ olmayan kaynak düğümünden ADÜ'ye) sürecini ifade etmekte ve $c_{i k j}$ karar değişkeni kara yolu maliyeti ile çarpılmaktadır. İkinci parçası, transfer (ADÜ'den ADÜ'ye) sürecini ifade etmekte ve $b_{k m j}$ karar değişkeni hava yolu maliyeti ve maliyet azaltma faktörü olan $\alpha$ ile çarpılmaktadır. Üçüncü parçası, dağıtım (ADÜ'den ADÜ olmayan varış noktasına) sürecini ifade etmekte ve $a_{m j}$ karar değişkeni kara yolu maliyetine ilaveten $\delta$ katsayısı ile çarpılmaktadır. Dördüncü parçası, ADÜ olarak seçilmeyen düğümler arasında ADÜ kullanmadan direkt gidişi ifade etmekte ve $e_{i j}$ karar değişkeni kara yolu maliyeti ile çarpılmaktadır.

(2) numaralı kısıt, her ildeki tüm şubelerin talebinin karşılandığını garanti etmektedir. Kısıt bu işlemi, $j$ düğümüne herhangi bir $m$ düğümünden gelebilecek muhtemel tüm akışları, tüm $i$ düğümlerinden $j$ düğümüne sevk edilen akış miktarına eşitleyerek gerçekleştirir.

(3) numaralı kısıt akışları dengeler ve akış kaybını engeller. Kısıt bu işlemi $i$ düğümüne gelmesi ve çıkması muhtemel tüm akışları ifade ederek gerçekleştirir. Kısıtın sağ tarafında, $i$ düğümüne gelebilecek tüm muhtemel akışlar, sol tarafinda, $i$ düğümünden çıkabilecek tüm muhtemel akışlar yer almaktadır.

(4) numaralı kısıt, ADÜ'ler arası akışı (transfer) ifade eden $b_{k m j}$ karar değişkenin, yalnızca $k$ ve $m$ düğümlerinin ADÜ olarak seçilmesi durumunda değer almasını sağlar.

(5) numaralı kısıt, ADÜ'ler arası akışı (transfer) ifade eden $b_{k j j}$ karar değişkeninin, yalnızca $k$ ve $j$ düğümlerinin ADÜ olarak seçilmesi durumunda değer almasını sağlar.

(6) numaralı kısıt, ADÜ olmayan kaynak noktasından ADÜ'lere olan akışı (toplama) ifade eden $c_{i k j}$ karar değişkeninin yalnızca $k$ düğümünün ADÜ olarak seçilmesi durumunda değer almasını sağlar.

(7) numaralı kısıt, kaynak noktası olan $i$ düğümünün ADÜ olarak seçilmesi durumunda $c_{i k j}$ ve $e_{i j}$ karar değişkenlerinin değer almamasını sağlar. Bu iki kısıt vasıtasıyla $c_{i k j}$ karar değişkeni, yalnızca $i$ düğümünün ADÜ olmayan düğüm, $k$ düğümünün $\mathrm{ADÜ} \mathrm{olduğu}$ durumda değer alabilir.

(8) numaralı kısıt, herhangi bir kaynak-varış noktası arasındaki akışın en fazla iki ADÜ’ye uğrayarak tamamlanmasını sağlar. Bu kısıt vasıtasıyla, mesafeler arasında üçgensel eşitsizliğin sağlanamamasından kaynaklanabilecek ikiden fazla ADÜ gezme işlemi engellenmiş olur. Kısıt bu işlemi, ADÜ olarak seçilen $k$ ilinden çıkan akışlar toplamının üst sınırını kullanarak yapar. Böylece, ADÜ olarak seçilen bir $k$ iline, ADÜ olarak seçilen başka bir ilden akış geldiğinde bu akış, $a_{m j}$ dağıtım (ADÜ'den ADÜ olmayan varış noktasına) karar değişkeni ile direkt olarak $j$ iline gitmeye zorlanır.

(9) numaralı kısıt kapasite kısıtıdır. Havaalanı bulunan " 42 " ilde kuruma ait bir veya birden fazla konaklama tesisi bulunmaktadır ve bu tesisler belirli bir kapasiteye sahiptir. ADÜ olmaya aday düğümler için kapasiteler, o ilde bulunan konaklama tesislerinin 
yatak kapasiteleri toplanarak hesaplanmıştır. Bu kısıt, ADÜ olarak seçilen bir $k$ düğümüne, ADÜ olarak seçilen ve ADÜ olarak seçilmeyen tüm düğümlerden gelen akış toplamının, $k$ düğümünün kapasitesini geçmesini engeller.

(10) numaralı kisıt $i$ düğümünün ADÜ olarak seçilmesi durumunda $e_{i j}$ karar değişkeninin değer almamasını, (11) numaralı kısıt $j$ düğümünün ADÜ olarak seçilmesi durumunda $e_{i j}$ karar değişkeninin değer almamasını sağlar. Başka bir ifadeyle (10) ve (11) numaralı kısıtlar $e_{i j}$ karar değişkeninin yalnızca $i$ ve $j$ düğümlerinin ADÜ olarak seçilmediği durumda değer alabilmesini sağlar.

(12), (13), (14) ve (15) numaralı kisitlar, modelde yer alması mümkün olmayan karar değişkenlerini " 0 " yapmak amacıyla yazılmış kısıtlardır.

(16) numaralı kısıt, $Y_{k}$ karar değişkeninin " 0 ” ya da "1" değerini almasını sağlar.

(17) numaralı kısıt, modelde yer alan tüm karar değişkenlerinin 0'dan büyük ve tamsayılı değerler almasını sağlar.

\subsection{Modelin Sonuçları (Results of the Model)}

Önerilen model, GAMS IDE 2.0.34.19 yazılımı ile kodlanmış ve CPLEX 10. 1 çözücüsü ile en iyi çözüme ulaşılmıştır. Modelde 659,521 adet tamsayı değişken ve 7,995 adet kısıt bulunmaktadır. En iyi çözümde amaç fonksiyon değeri 1,964,973,8 TL olarak hesaplanmıştır. Mevcut sistemde toplam taşıma maliyeti 2,755,712 TL'dir. Önerilen model \%40 oranında maliyet avantajı sağlamaktadır.

Çözüm sonucunda; aday ADÜ konumundaki 42 adet havaalanından 35 tanesi ADÜ olarak seçilmiştir. Çözüm sonuçları incelendiğinde; farklı düğüm noktalarından çıkarak aynı varış noktasına gidecek olan akışların ADÜ'lerdeki yük birleştirmelerinin etkili bir şekilde yapıldığı görülmüştür.

Farklı $\alpha$ ve $\delta$ değerleri için yapılan parametrik analiz neticesinde; $\alpha$ 'nın değerindeki artışların akışların ADÜ kullanarak gerçekleşme oranını azalttığı, $\alpha$ 'nın değerindeki azalmanın ise akışların ADÜ kullanarak gerçekleşme oranı artırdığı görülmüştür. $\delta$ değerindeki azalmanın, seçilen ADÜ sayısını azalttığı, $\delta$ değerindeki artışın ise seçilen ADÜ sayısının artmasına neden olduğu gözlemlenmiştir.

Tablo 1'de model tarafindan belirlenmiş örnek güzergâhlar sunulmuştur. Tabloda koyu renkle işaretlenmiş şehirler modelin ADÜ olarak önerdiği yerlerdir. Tablo 1'de yer alan veriler Aydın-Bitlis arasındaki personel sevkiyatının; Aydın'dan ADÜ olarak seçilen Denizli'ye kara yolu ile bireysel olarak,
Denizli'den yine ADÜ olarak seçilen Muş’a uçakla toplu olarak, Muş’tan Bitlis'e kara yolu ile toplu olarak yapılması gerektiğini göstermektedir.

Tablo 1. Örnek güzergâhlar (Sample routes)

\begin{tabular}{|c|c|c|}
\hline $\begin{array}{l}\text { Çıkış } \\
\text { Noktası }\end{array}$ & $\begin{array}{l}\text { Varış } \\
\text { Noktası }\end{array}$ & Kullanılacak Güzergâh \\
\hline Mersin & Ăgrı & Mersin-Adana-Ăgrı \\
\hline Adıyaman & Bitlis & Adıyaman-Batman-Bitlis \\
\hline Erzurum & Ăgrı & Erzurum-Ăgrı \\
\hline Çankırı & Hakkâri & $\begin{array}{l}\text { Çankırı-Amasya-Van- } \\
\text { Hakkâri }\end{array}$ \\
\hline Bilecik & Ardahan & $\begin{array}{l}\text { Bilecik-Ankara-Kars- } \\
\text { Ardahan }\end{array}$ \\
\hline Antalya & Van & Antalya-Van \\
\hline Tunceli & Ăğrı & Tunceli-Bingöl-Ağrı \\
\hline Balıkesir & Muş & Balıkesir-Bursa-Muş \\
\hline Aydın & Bitlis & Aydın-Denizli-Muş-Bitlis \\
\hline Tunceli & Antalya & Tunceli-Elažg-Antalya \\
\hline Gaziantep & Iğdır & Gaziantep-Iğdır \\
\hline Kirklareli & Van & Kurklareli-İstanbul-Van \\
\hline Manisa & Hakkâri & $\begin{array}{l}\text { Manisa-İzmir-Şırnak- } \\
\text { Hakkâri }\end{array}$ \\
\hline Ardahan & Kars & Ardahan-Kars \\
\hline Sakarya & Bitlis & $\begin{array}{l}\text { Sakarya-Kocaeli-Bingöl- } \\
\text { Bitlis }\end{array}$ \\
\hline Isparta & Iğdır & Isparta-Konya-Iğdır \\
\hline Kütahya & Ăgrı & Kütahya-Ağrı \\
\hline Malatya & Ardahan & Malatya-Kars-Ardahan \\
\hline Osmaniye & Erzurum & $\begin{array}{l}\text { Osmaniye- } \\
\text { Kahramanmaraş-Erzurum }\end{array}$ \\
\hline Muğla & Hakkâri & Muğla-Şırnak-Hakkâri \\
\hline Bitlis & Ankara & Bitlis-Muş-Ankara \\
\hline Aksaray & Ăgrı & Aksaray-Nevşehir-Ăğrı \\
\hline Bitlis & Siirt & Bitlis-Siirt \\
\hline Tunceli & Ankara & Tunceli-Sivas-Ankara \\
\hline Ordu & Hakkâri & Ordu-Trabzon-Van-Hakkâri \\
\hline Hakkâri & Bitlis & Hakkâri-Van-Bitlis \\
\hline Bitlis & Adana & Bitlis-Batman-Adana \\
\hline Hakkâri & Antalya & Hakkâri-Şırnak-Antalya \\
\hline I ğdır & Ankara & Iğdır-Ankara \\
\hline
\end{tabular}

Elde edilen çözümler mevcut sistemden farklı olarak değişik güzergâhlar için farklı havaalanlarının kullanılması gerektiğini göstermiştir. Örneğin; Tunceli ilindeki çalışanlar, Ağrı'ya giderken Bingöl, Antalya'ya giderken Elazı̆̆g, Ankara'ya giderken Sivas havaalanlarını kullanmaktadır. Elde edilen sonuçlar aynı kaynak noktasından çıkıp farklı varış noktalarına gidecek olan akışların aynı hava alanını kullanma zorunluluğunun kaldırılması ve yük birleştirmelerinin doğru ADÜ'lerde yapılması gerektiğini göstermektedir.

Geleneksel ADÜ yer seçim problemlerinin temel varsayımlarından bir tanesi, akışların mutlaka ADÜ kullanma zorunluluğudur. Bu kısıtın gevşetilmesi ile elde edilen en iyi çözümde çalışanların ADÜ olarak seçilmeyen hangi kaynak-varış çiftleri arasında kara yolu ile münferit olarak taşınması gerektiği Tablo 2'de gösterilmiştir. 
Tablo 2. ADÜ kullanmadan direkt gidişe müsaade edilen güzergâhlar (Available routes which allow direct flows without using hub)

\begin{tabular}{|c|c|c|}
\hline $\begin{array}{l}\text { Kaynak } \\
\text { Noktası }\end{array}$ & $\begin{array}{c}\text { Varış } \\
\text { Noktası }\end{array}$ & $\begin{array}{c}\text { Kullanılacak } \\
\text { Güzergâh }\end{array}$ \\
\hline \multirow{3}{*}{ Artvin } & Erzincan & Artvin-Erzincan \\
\hline & Erzurum & Artvin-Erzurum \\
\hline & Ardahan & Artvin-Ardahan \\
\hline \multirow{2}{*}{ Diyarbakır } & Mardin & Diyarbakır-Mardin \\
\hline & Tunceli & Diyarbakır-Tunceli \\
\hline \multirow{2}{*}{ Erzincan } & Erzurum & Erzincan-Erzurum \\
\hline & Tunceli & Erzincan-Tunceli \\
\hline \multirow{4}{*}{ Erzurum } & Erzincan & Erzurum-Erzincan \\
\hline & Mardin & Erzurum-Mardin \\
\hline & Tunceli & Erzurum-Tunceli \\
\hline & Ardahan & Erzurum-Ardahan \\
\hline \multirow{3}{*}{ Giresun } & Erzincan & Giresun-Erzincan \\
\hline & Erzurum & Giresun-Erzurum \\
\hline & Tunceli & Giresun-Tunceli \\
\hline \multirow{3}{*}{ Gümüşhane } & Erzincan & Gümüşhane-Erzincan \\
\hline & Erzurum & Gümüşhane-Erzurum \\
\hline & Tunceli & Gümüşhane-Tunceli \\
\hline \multirow{2}{*}{ Mardin } & Diyarbakır & Mardin-Diyarbakır \\
\hline & Erzurum & Mardin-Erzurum \\
\hline \multirow{3}{*}{ Ordu } & Erzincan & Ordu-Erzincan \\
\hline & Erzurum & Ordu-Erzurum \\
\hline & Tunceli & Ordu-Tunceli \\
\hline \multirow{2}{*}{ Rize } & Diyarbakır & Rize-Diyarbakır \\
\hline & Ardahan & Rize-Ardahan \\
\hline \multirow{3}{*}{ Tunceli } & Diyarbakır & Tunceli-Diyarbakır \\
\hline & Erzincan & Tunceli-Erzincan \\
\hline & Erzurum & Tunceli-Erzurum \\
\hline \multirow{3}{*}{ Bayburt } & Diyarbakır & Bayburt-Diyarbakır \\
\hline & Erzincan & Bayburt-Erzincan \\
\hline & Erzurum & Bayburt-Erzurum \\
\hline Ardahan & Erzincan & Ardahan-Erzincan \\
\hline
\end{tabular}

Marin [1]'in önerdiği modelde akışlar ADÜ kullanmak zorundadır. Ele alınan problem bu varsayım altında çözüldüğünde en iyi çözüm değeri 2,005,964,63 TL olarak gerçekleşmiştir. Önerilen modelde, ADÜ kullanma zorunluluğu gevşetilerek yaklaşık 40,990,83 TL (\%2) maliyet avantaj1 sağlandığı görülmüştür. Bu sonuçlara dayanarak ADÜ kullanma zorunluluğu yerine karma bir sistemle daha düşük maliyetler elde edilebileceği düşünülmektedir.

\section{SONUÇLAR (CONCLUSIONS)}

Çalışmada, dönemsel olarak çalışanlarının bir bölümünü belirli noktalar arasında taşıtması gereken bir kamu kurumuna yönelik bir ana dağıtım üssü yer seçim problemi ele alınmıştır. Kurum yönetimimin beklentilerinin ortaya konulmasinı müteakip, literatürde yapılan inceleme neticesinde, ADÜ yer seçim problemlerinin çözümü için geliştirilen matematiksel modellerin ele alınan problemin temel karakteristiklerini karşılamada yetersiz kaldığ 1 görülmüştür. $\mathrm{Bu}$ çalışmada, ele alınan problemin yapısına uygun olarak, literatürde yer alan ADÜ yer seçim problemlerine yeni bir boyut kazandırılmıştır.
Problem, şebekedeki düğümler arasındaki mesafelerde üçgensel eşitsizliğin sağlanamadığ1, kesikli uzayda yer alan, çok atamalı, ADÜ olarak seçilmeyen kaynak - varış çiftleri arasındaki akışlarda ADÜ kullanmadan direkt gidişe müsaade eden ADÜ olarak seçilen düğümlerin kapasitelerini, hem ADÜ, hem de ADÜ olarak seçilmeyen dügüumlerden gelen akışların etkilediği ADÜ yer seçim problemi olarak tasarlanmıştır. Çalışmada, Marin [1] tarafından geliştirilen sabit maliyetli, çok atamalı, kapasite kısıtlı yapıya sahip matematiksel modelden hareketle, problemin gereksinimlerine özgü, yeni bir matematiksel model geliştirilmiştir. Problemin yapısına uygun olarak geliştirilen matematiksel model literatürde yer alan ADÜ yerleşim problemlerinden farklı olarak, şayet daha ekonomikse düğümler arasında doğrudan akışa izin vermektedir. Literatürde yer alan ve ADÜ olarak seçilmeyen düğümler arasında doğrudan akışa izin vermeyen matematiksel modellerle karşılaştırıldığında önerilen modelin maliyet avantajı yarattığı görülmüştür. $\mathrm{Bu}$ değerlendirmeler 1şığında; problemin yapısına bağlı olarak salt ADÜ-ADÜ akışı yerine doğrudan akışlara da izin veren karma modellerin daha ekonomik sonuçlar üretebileceği değerlendirilmektedir.

$\mathrm{Bu}$ konuyla ilgili olarak ileride yapılabilecek çalışmalara yönelik şu önerileri sıralamak mümkündür:

- Matematiksel model, belirsizlik durumunun ortaya koyduğu durumları içerecek şekilde stokastik olarak çalışılabilir. Böylece, problemin gerçek karakteristiklerine çok daha yakın sonuçlar elde edilebilir.

- Matematiksel modelin zaman pencereli olarak düşünülmesiyle, ADÜ'lerin kapasitelerinin daha uygun şekilde kullanılması ve yerleştirme atama kararlarının gerçeğe en yakın şekilde bulunabilmesi sağlanabilir.

\section{KAYNAKLAR (REFERENCES)}

1. Marín, A., "Formulating and Solving Splittable Capacitated Multiple Allocation Hub Location Problems", Computers \& Operations Research, Cilt 32, No 12, 3093-3109, 2005.

2. O'kelly, M.E., "The Location of Interacting Hub Facilities", Transportation Science, Cilt 20, No 2, 92-106, 1986.

3. O'kelly, M.E., "A Quadratic Integer Program for the Location of Interacting Hub Facilities", European Journal of Operational Research, Cilt 32, No 3, 393-404, 1987.

4. Ernst, A.T. ve Krishnamoorthy M.. "Efficient Algorithms for the Uncapacitated Single Allocation P-Hub Median Problem", Location Science, Cilt 4, No 3, 139-154, 1996.

5. Mayer, G. ve Wagner, B., "HubLocator: an Exact Solution Method for the Multiple Allocation Hub 
Location Problem", Computers \& Operations Research, Cilt 29, No 6, 715-739, 2002.

6. O'kelly, M.E., "Hub Facility Location with Fixed Costs", Papers in Regional Science, Cilt 71, No 3, 293-306, 1992.

7. Campbell, J.F., "Integer Programming Formulations of Discrete Hub Location Problems", European Journal of Operational Research, Cilt 72, No 2, 387-405, 1994.

8. Campbell, J.F., "Hub Location and the P-Hub Median Problem", Operations Research, Cilt 44, No 6, 923-935, 1996.

9. Aykin, T., "On a Quadratic Integer Program for the Location of Interacting Hub Facilities", European Journal of Operational Research, Cilt 46, No 3, 409-411, 1990.

10. Aykin, T., "Lagrangean Relaxation Based Approaches to Capacitated Hub-and-Spoke Network Design Problem", European Journal of Operational Research, Cilt 79, No 3, 501523, 1994.

11. Aykin, T., "Networking Policies for Hub-andSpoke Systems with Application to the Air Transportation System", Transportation Science, Cilt 29, No 3, 201-221, 1995a.

12. Aykin, T., "The Hub Location and Routing Problem", European Journal of Operational Research, Cilt 83, No 1, 200-219, 1995b.

13. Klincewicz, J.G., "Heuristics for the P-Hub Location Problem", European Journal of Operational Research, Cilt 53, No 1, 25-37, 1991.

14. Klincewicz, J.G., "Avoiding Local Optima in the p-Hub Location Problem Using Tabu Search and GRASP”, Annals of Operations Research, Cilt 40, No 1, 283-302, 1992.

15. Ebery, J., Krishnamoorthy, M., Ernst A. ve Boland N., "The Capacitated Multiple Allocation Hub Location Problem: Formulations and Algorithms", European Journal of Operational Research, Cilt 120, No 3, 614-631, 2000.

16. Sasaki, M. ve Fukushima, M., "On the Hub-andSpoke Model with Arc Capacity Constraints", Journal of the Operations Research Society of Japan, Cilt 46, No 4, 409-428, 2003.

17. Boland, N., Krishnamoorthy, M., Ernst, A.T. ve Ebery, J., "Preprocessing and Cutting for Multiple Allocation Hub Location Problems", European Journal of Operational Research, Cilt 155, No 3, 638-653, 2004.

18. Rodriguez, V., Alvarez, M.J. ve Barcos, L., "Hub Location Under Capacity Constraints", Transportation Research Part E: Logistics and Transportation Review, Cilt 43, No 5, 495-505, 2007.
19. Rodriguez-Martin, I. ve Salazar-Gonzalez, J.J., "Solving a Capacitated Hub Location Problem", European Journal of Operational Research, Cilt 184, No 2, 468-479, 2008.

20. Gelareh, S. ve Pisinger, D., "Fleet Deployment, Network Design and Hub Location of Liner Shipping Companies", Transportation Research Part E: Logistics and Transportation Review, Cilt 47, No 6, 947-964, 2011.

21. Sender, J. ve Clausen U., "Heuristics for Solving a Capacitated Multiple Allocation Hub Location Problem with Application in German Wagonload Traffic", Electronic Notes in Discrete Mathematics, Cilt 41, 13-20, 2013.

22. Shahabi, M. ve Unnikrishnan, A., "Robust Hub Network Design Problem", Transportation Research Part E: Logistics and Transportation Review, Cilt 70, 356-373, 2014.

23. Karimi, H. ve Setak, M., "Proprietor and Customer Costs in the Incomplete Hub LocationRouting Network Topology", Applied Mathematical Modelling, Cilt 38, No 3, 10111023, 2014.

24. O'kelly, M.E. ve Miller, H.J., "The Hub Network Design Problem: a Review and Synthesis", Journal of Transport Geography, Cilt 2, No 1, 31-40, 1994.

25. Alumur, S. ve Kara, B.Y., "Network Hub Location Problems: The State of the Art", European Journal of Operational Research, Cilt 190, No 1, 1-21, 2008.

26. Bryan, D.L. ve O’kelly, M.E., "Hub-and-Spoke Networks in Air Transportation: an Analytical Review", Journal of Regional Science, Cilt 39, No 2, 275-295, 1999.

27. Kara, B. Y. ve Tansel, B.C., "The SingleAssignment Hub Covering Problem: Models and Linearizations", Journal of the Operational Research Society, Cilt 54, No 1, 59-64, 2003.

28. Ermiş, M. ve Ülengin, F., "Merkez Üslerin Konumlandırılması Probleminin Hopfield-Tank Yapay Sinir Ağları ile Çözülmesi” İTÜ Dergisi/D, Cilt 5, No 1, 228-238, 2006.

29. Özger, A. ve Oktal, H., "Havayolu Kargo Taşımacılığında Kapasite Sınırı Olmayan Çok Atamalı P-Ana Dağıtım Üssü Medyan Problemine Tamsayılı Model Yaklaşımı", Journal of Aeronautics \& Space Technologies/Havacilik ve Uzay Teknolojileri Dergisi, Cilt 4, No 1, 2008.

30. Karayolları Genel Müdürlüğü 11 Mart 2014, www.kgm.gov.tr/Sayfalar/KGM/Site $\mathrm{Tr} /$ Root/ Uzakliklar.aspx. 